\title{
geosciences
}

ISSN 2076-3263

www.mdpi.com/journal/geosciences

Article

\section{Flash Floods in the Guelmim Area/Southwest Morocco-Use of Remote Sensing and GIS-Tools for the Detection of Flooding-Prone Areas}

\section{Barbara Theilen-Willige ${ }^{1, *}$, Abdessamad Charif ${ }^{2}$, Abdelhadi El Ouahidi ${ }^{2}$, Mohamed Chaibi ${ }^{2}$, Mohamed Ayt Ougougdal ${ }^{2}$ and Halima AitMalek ${ }^{2}$}

1 Technische Universität Berlin (TUB), Institute of Applied Geosciences; Ernst-Reuter-Platz 1, D-10587 Berlin, Germany

2 University of Cadi Ayyad, Polydisciplinary Faculty, Safi, 4162, Route de Sidi Bouzid, 46000 Safi, Morocco; E-Mails: a.charif@uca.ma (A.C.); abdelhadielouahidi@gmail.com (A.E.O.); haibimohamed@gmail.com (M.C.); aytctt@yahoo.fr (M.A.O.); h.aitmalek@uca.ma (H.A.)

* Author to whom correspondence should be addressed;

E-Mail: Barbara.Theilen-Willige@t-online.de; Tel.: +49-7771-1868.

Academic Editors: Ken McCaffrey and Jesus Martinez-Frias

Received: 11 January 2015 / Accepted: 12 May 2015 / Published: 27 May 2015

\begin{abstract}
The violent storms of 22-30 November 2014, resulted in flash floods and wadi floods (rivers) in large parts of Southern Morocco, at the foot of the Atlas Mountains. The Guelmim area was the most affected part with at least 32 fatalities and damages due to inundations. The flooding hazard in the Guelmim region initiated this study in order to investigate the use of remote sensing and geographic information system (GIS) for the detection and identification of areas most likely to be flooded in the future again due to their morphologic properties during similar weather conditions. By combining morphometric analysis and visual interpretation based on Landsat 8 satellite data and derived images such as water index (NDWI) images, areas with relatively higher soil moisture and recently deposited sediments were identified. The resulting maps of weighted overlay procedures, aggregating causal, morphometric factors influencing the susceptibility to flooding (lowest height levels, flattest areas), allowed for the distinguishing of areas with higher, medium and lower susceptibility to flooding. Thus, GIS and remote sensing tools contribut to the recognition and mapping of areas and infrastructure prone to flooding in the Guelmim area.
\end{abstract}

Keywords: flooding; southern Morocco; remote sensing; GIS 


\section{Introduction}

Leaving aside droughts, floods are one of the most dangerous meteorological hazards in Morocco, followed by wind-/sandstorms, with the largest frequency of occurrence and the largest number of victims [1]. Heavy rains often induce floods in Morocco, including flash floods, riverine floods and mud floods during the rainy season [2,3]. Violent storms on 22-30 November 2014 resulted in flash floods and wadi (rivers) flooding in a large part of southern Morocco, at the foot of the Atlas Mountains. Although flash floods are not uncommon in southern Morocco, those in November 2014 were exceptional. Figure 1 provides an overview of the position of the investigation area and the cloud situation in November 2014. These torrential rains that especially hit the region of Guelmim, a town about $200 \mathrm{~km}$ south of Agadir (Figure 1), caused considerable damage, so that the region of Guelmim was declared a "disaster area." Following the overflow, after the breaking of the wadi levees, several neighborhoods were completely submerged. Many roads were closed and power and telephone networks were damaged, as documented by A. Charif in Figure 2, showing images of the flooding event and resulting damages in and near Guelmim. A hundred "adobe houses" were totally or partially destroyed, and dozens of roads blocked, including six national roads. Rainfall intensity reached $250 \mathrm{~mm}$ in a few hours on some mountains of the Anti-Atlas. Then water flowed down the slopes to the semi-desert plains of the Moroccan Southwest [4]. The torrential rains caused flooding of Wadi Bousafen, about $32 \mathrm{~km}$ in the south of Guelmim and the wadi Oum el Aachar in the west of Guelmim, carting trees and vehicles and submerging roads and bridges. The flooding turned the rivers into a raging torrents [4].

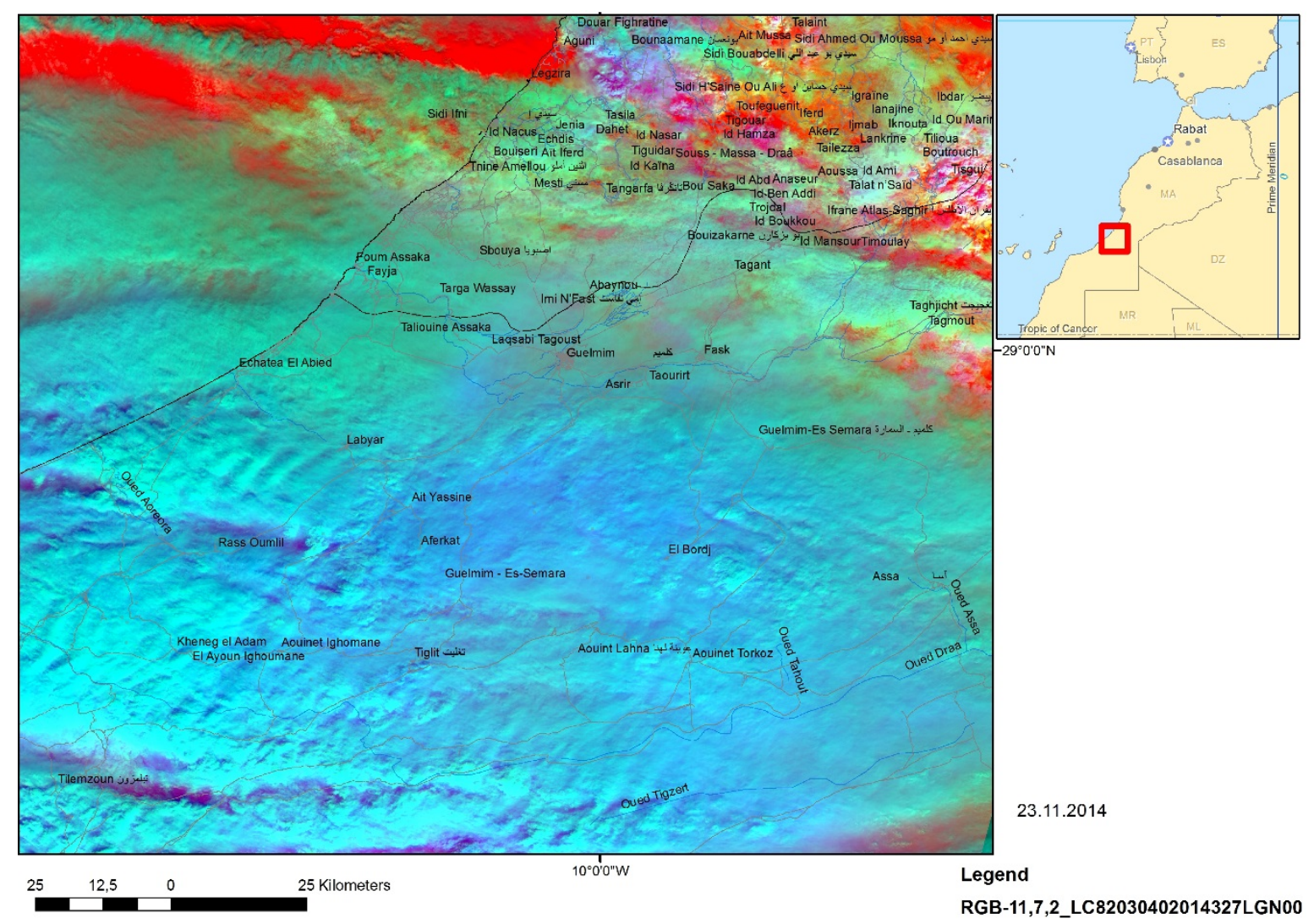

Figure 1. Cloud cover visible on a Landsat 8 scene of the Guelmim area related to heavy rainfall on 23 November 2014. 


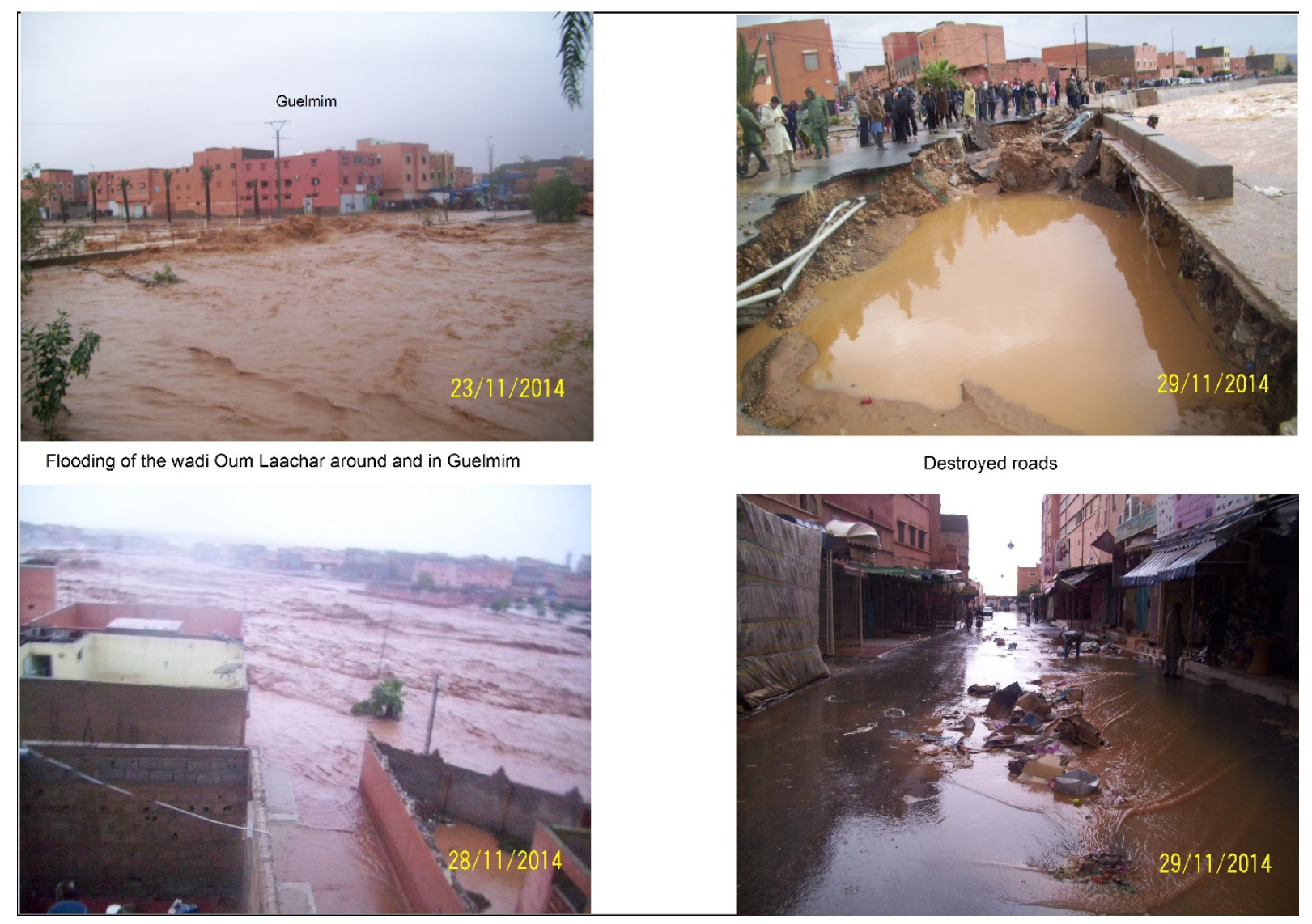

Figure 2. Flooding of the Wadi Oum Laachar near and within in the city of Guelmim. The bridge is partially submerged by the waters of the river and the road was destroyed by floods. (Images: Abdessamad Charif, November 2014).

This flooding event rose the question of whether and how remote sensing and GIS tools could be used in an effective manner in order to contribute to a better understanding of the factors leading to this flooding hazard and how to mitigate damage in future by providing maps of areas that have been flooded in the past and areas that are susceptible to flooding due to their morphologic settings during extreme precipitation events.

\section{Geographic and Geologic Overview}

The province of Guelmim is characterized by its oasis landscapes. Agriculture is the main activity in this region. The geographical distribution of population, shows a high concentration along the main roads and the banks of the main wadis.

The Guelmim area has an arid to semi-arid desert climate. The average annual rainfall averages generally up to $120 \mathrm{~mm}[5,6]$. The distribution of rainfall in the year shows two seasons, dry from April to September and wet from November to March. Most precipitation falls in December, with an average of $26 \mathrm{~mm}$. The driest month is June with about $1 \mathrm{~mm}$ of precipitation.

The topography of the Guelmim basin is characterized by broader valleys and depressions surrounded by hills with height differences of more than $500 \mathrm{~m}$ (Figure 3). With a total area of about 10,000 $\mathrm{km}^{2}$, the Guelmim basin is subdivided into several depressions or "feijas," of which the most important are: 
1. Northern part of the Guelmim basin: The great "internal Feija" Guelmim-Bouizakerne following the southern fallout primary limestone of the Anti-Atlas. It widens from east to west, reaching 7-10 km in the valley of Wadi Umm Al Achar, between the mountains of Ait Baamrane and Jbel Tayert; its altitude varies from $600 \mathrm{~m}$ to $200 \mathrm{~m}$ north to south (position: 1 in Figure 3).

2. At the center: The valley of Wadi Seyyad-Ouerguennoun, consisting of Precambrian and Georgian mass, form an "external Feija" $5 \mathrm{~km}$ wide on average (position: 2 on Figure 4).

3. In the southwest, the depression is bordered by the northern flank of Jebel Guir-Taissa, which appears narrow, and parallel gutters between quartzite ridges of the upper part of the Acadian and those Ordovician Aït Lahcen, reach $350 \mathrm{~m}$ to $550 \mathrm{~m}$ [7,8]. The river system opens into a plain regular and low gradient $(0.5 \%)$ practice where a natural spreading of flood waters is controlled by the Ait Ahmed dam (position: 3 on Figure 4).

Rivers discharging from the mountains surrounding the sedimentary basins contribute to an enormous input of sedimentary loads, almost in the scope of flash flood hazards, covering the foot-slopes and basins.
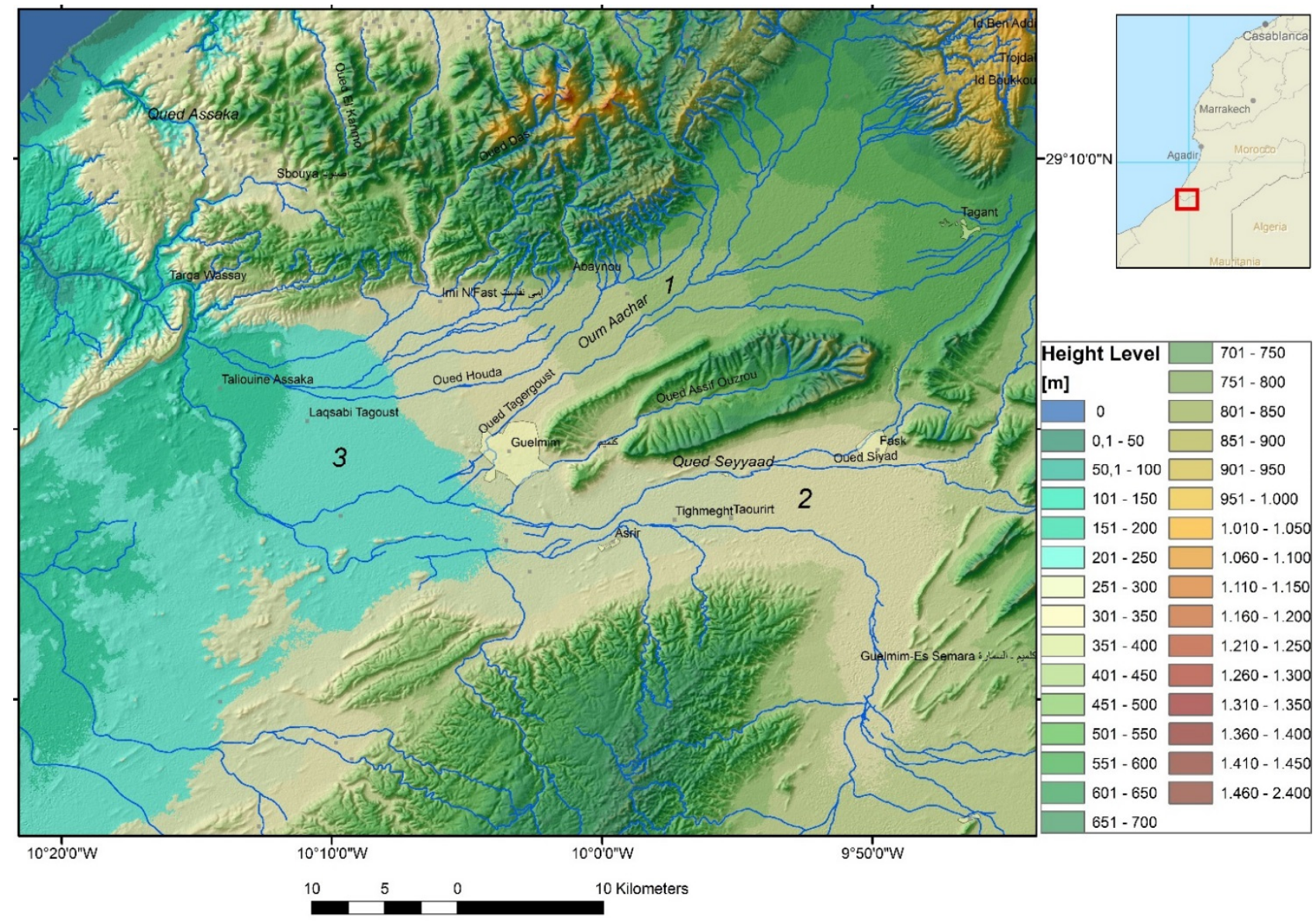

Figure 3. Height level map based on SRTM DEM-data.

Figure 4 shows a 3D perspective Landsat 8 satellite view of the study area visualizing the geomorphologic setting. 
The drainage pattern in the Guelmim area is often inactive as a dry-valley network during low flow periods in summer. Most of the rivers are seasonal and mostly dry except during the period from December to March when the beds allow flood water transportation. With the exception of flows generated by precipitation limited in time and intensity, surface waters are rare.

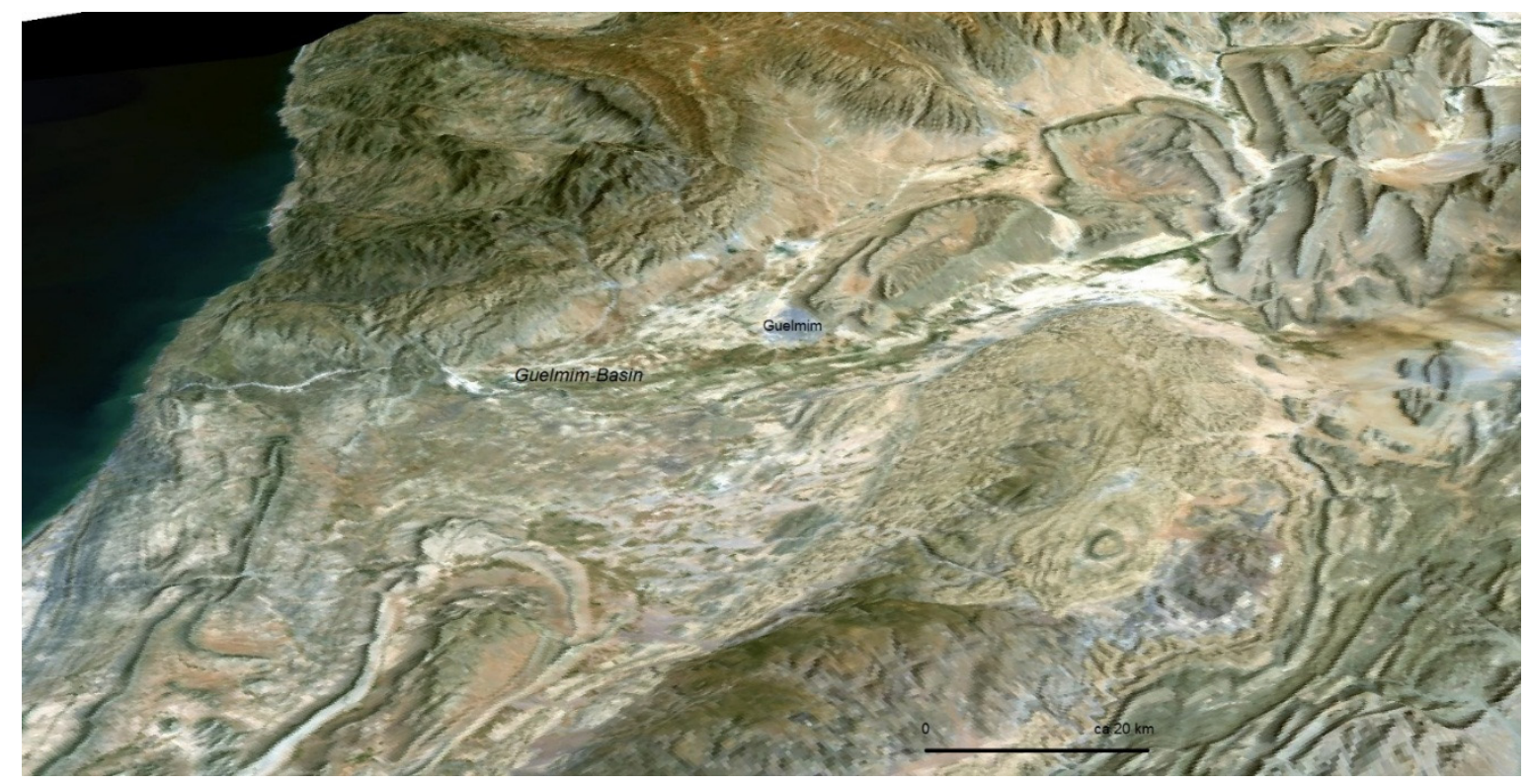

Figure 4. Perspective 3D view of a Landsat 8 image merged with ASTER DEM data of the Guelmim area facing north.

The depression in the southwest of Guelmim is situated in height levels between 250 and $300 \mathrm{~m}$. This depression is bordered in the west by coast-parallel, elongated hills and ridges forming barriers to surface water runoff and discharge into the Atlantic (Figure 3, depression area 3). This natural barrier is leading to water retention in case of high precipitation intensities and, thus, is one of the factors supporting the risk of flash floods. The dimension of the flash floods in the Guelmim area as at the end of November 2014 can be explained by these natural barriers allowing water discharge into the Atlantic in narrow riverbeds such as the Oued Assaka. Traces of former flooding events in the Guelmim basin are visible on the satellite images, including meandering drainage lines.

Mainly four wadis characterize the drainage pattern of the plain of Guelmim (Figure 5):

1. Oum Laachar originates from the northern Anti-Atlas and has a length of $62 \mathrm{~km}$ with a pool of $930 \mathrm{~km}^{2}$. Its main tributaries are located in the plains.

2. Oued Seyad arises on the southern slopes of the Anti-Atlas. It flows in an east-west direction along its length and receives numerous tributaries at its right bank. The most important are: Kelmt, Tanzirt, Taouimarht, Ifrane, Ben Rhezrou and Umm Aachar; the size of its watershed is $3175 \mathrm{~km}^{2}$ with a length of $147 \mathrm{~km}$. Dams implemented to derive the floodwaters at this wadi are Ait Ahmed, Ait Messaoud, Ait Me Hand, Umm Aghanim and Ouaroun,

3. Oued Noun Ouerg drains the southern area of the Anti-Atlas, the area of its basin is $2240 \mathrm{~km}^{2}$ with a length of $143 \mathrm{~km}$ and its watershed comprises about $2240 \mathrm{~km}^{2}$.

4. Oued Assaka is discharging into the Atlantic, fed from the confluence of three wadis: Achar Oum El Sayed and Ouergnoun, draining an area of $6500 \mathrm{~km}^{2}[9,10]$. 
When analyzing the morphological watershed area, it becomes obvious that the large size of the morphological catchment area supports the flash flood occurrence, concentrating surface water run-off and sediment load in the broader valleys and depressions (Figures 5 and 6). Figure 6 contains a topographic W-E cross-section visualizing the near-coast barrier.

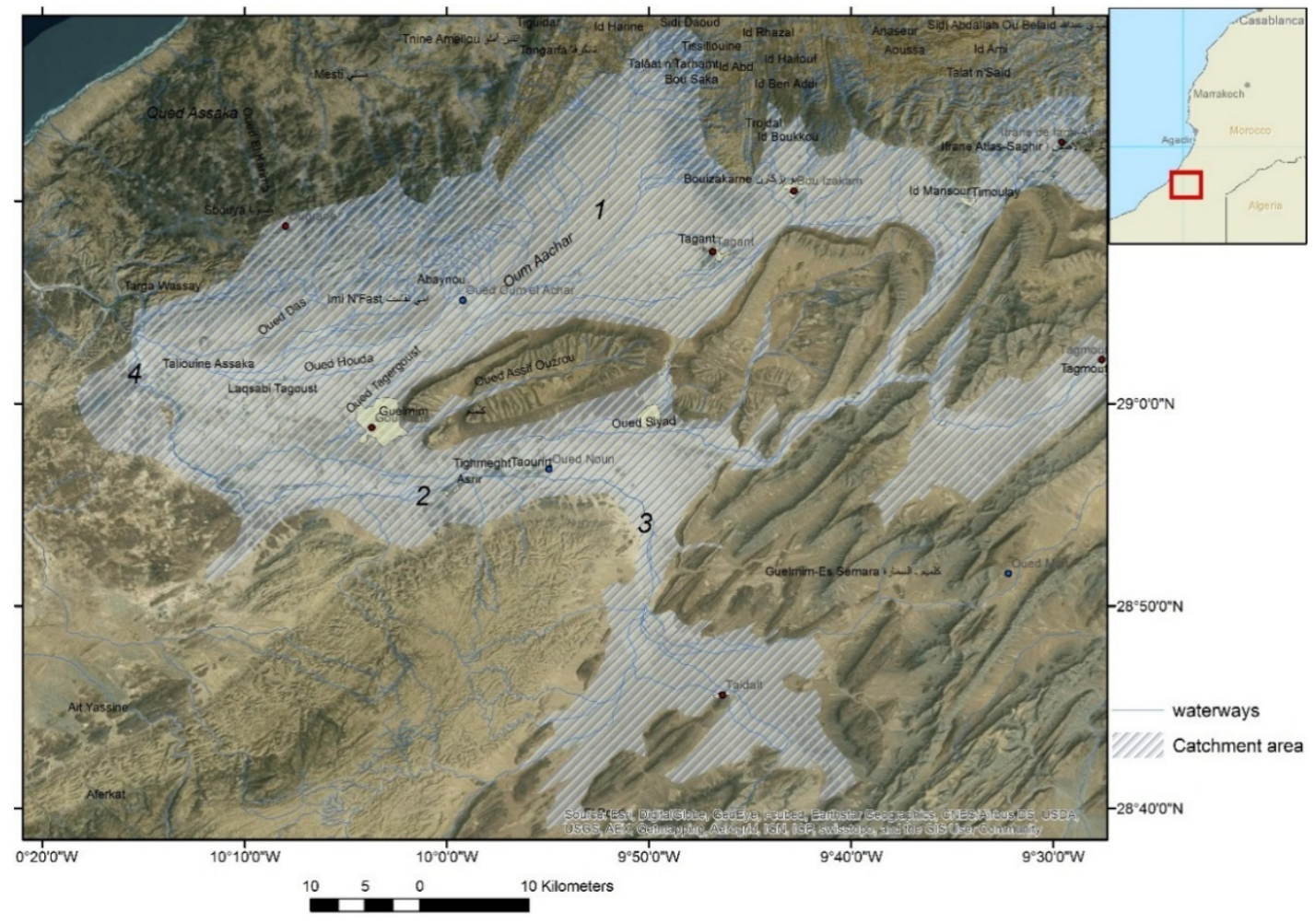

Figure 5. Morphologic catchment area of the Guelmim depression and main wadis (1) Oum Laachar; (2) Oued Sayad; (3) Oued Noun; (4) Oued Assaka.

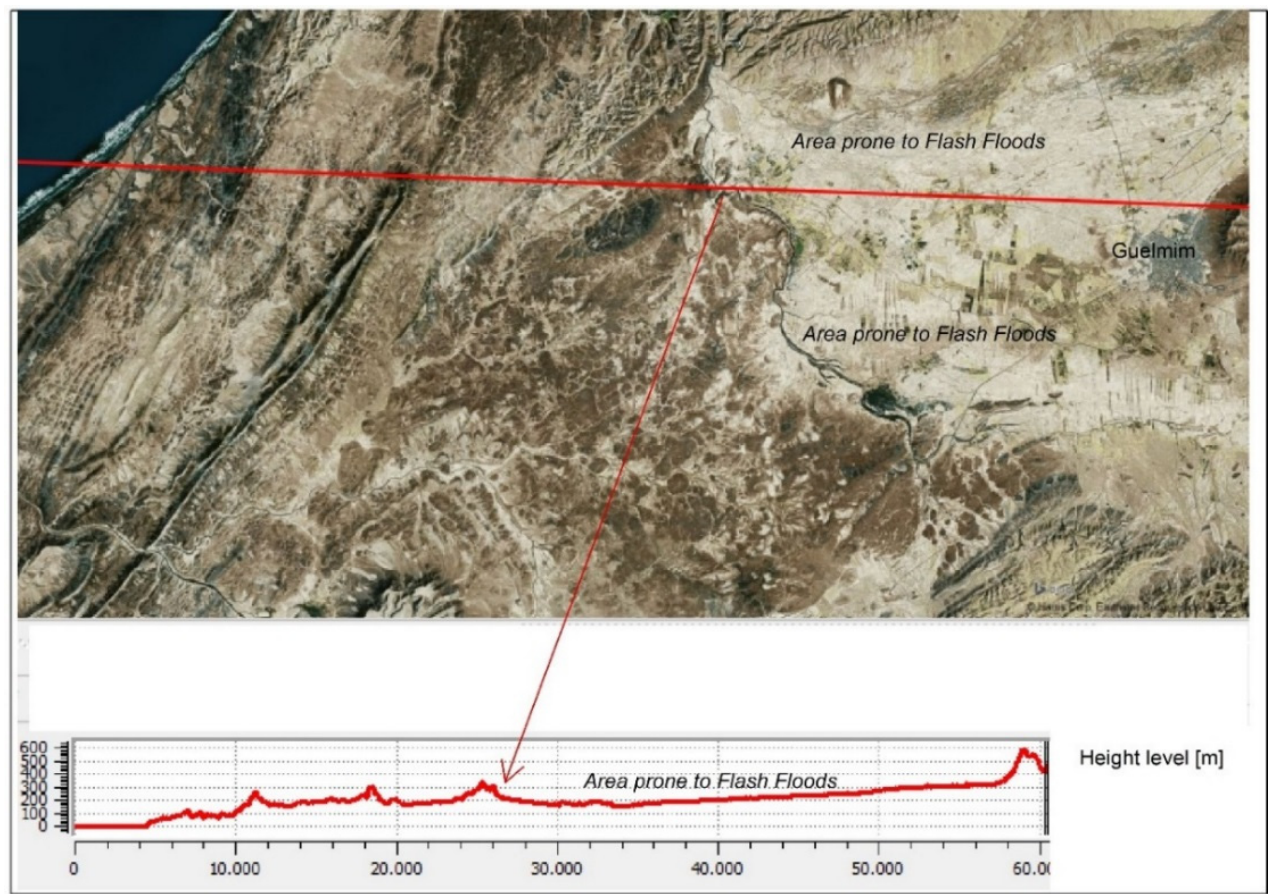

Figure 6. Topographic profile visualizing the coast-parallel barriers for surface water run-off. 


\section{Methods}

Satellite imageries and DEM data were used for generating an image-based GIS and combined with different geodata and other thematic maps such as geologic and tectonic maps, and precipitation data. The approach consists of the following steps:

(a) Morphometric analysis of the investigation area involving the quantitative analysis of the landforms based on DEM data aiming at the extraction of land surface parameters by using a set of numerical measures derived from DEMs such as slope steepness, curvature or convexity.

(b)Detection of areas with relatively higher surface water input than the environment based on the weighted overlay of causal, morphometric factors (lowest height level, lowest slope degree, etc.) influencing the susceptibility to flooding.

\subsection{Evaluations of Digital Elevation Model Data (DEM)}

In the areas with relatively higher surface water input as in depressions and valleys, usually the inundation processes are more intense than in the surrounding higher environment. Therefore, the investigations are focused on the detection of areas with relatively higher surface water input after precipitations due to their morphometric properties (lowest and flattest areas).

Digital elevation models (DEMs) provide an opportunity to quantify land surface geometry in terms of elevation and its derivatives. The morphometric analysis of digital elevation data helps as well to visualize the small-scaled variations in the surface, characterized for example by subtle changes of depressions and elevations. Morphometric maps such as slope gradient, hill shade, height level, and curvature maps were generated based on SRTM and ASTER digital elevation model (DEM) data using ArcGIS from ESRI and ENVI digital image processing software from EXELIS as well as open-source Quantum-GIS. From SRTM (1 Arc Second Global: $30 \mathrm{~m}$ spatial resolution) and ASTER DEM (30 m) data derived morphometric maps (slope gradient maps, drainage, etc.) were combined with lithologic and hydromorphologic information in a GIS database [11-13]. As the DEM data were gained by different satellite systems as optical sensors (ASTER) and radar sensors (SRTM), there are different constrictions in the accuracy of the data. Therefore, both datasets were used for correlation and testing. The limitation of the approach lies in the constricted accuracy of the SRTM and ASTER DEM datasets. However, it is suited to obtain a first basic overview of the susceptible areas and hazard perspectives according to a standardized approach with no costs for the DEM-data input. Of course, many further factors and data play an important role that (if available) should be included into the database. By combining some of the causal or preparatory factors in a georeferenced GIS environment those areas can be detected, where causal factors influencing the susceptibility to flooding occur aggregated and superimpose over each other.

In order to detect those areas, where causal factors are superimposing over each other, a weighted overlay procedure was carried out. It is aiming at the detection of areas with higher susceptibility to flooding by extracting geomorphologic, causal/preparatory factors such as lowest, local height levels and lowest slope degrees and, then, by aggregating these factors in the weighted overlay tool of ArcGIS. (As causal factors are considered further on the curvature, lithology, groundwater table level, vegetation cover and land use.) Causal factors determine the initial, favorable conditions for the occurrence of 
flooding while the triggering factors such as high precipitation rates determine more the timing. The triggering mechanisms are quite unpredictable, as they vary in time; however, the causal factors can be integrated as layers into a GIS.

The weighted overlay method takes into consideration the relative importance of the parameters and the classes belonging to each parameter (ESRI, online support). The basic pre-requisite for use of weighting tools of GIS is the determination of weights and rating values representing the relative importance of factors and their categories. The method starts by assigning an arbitrary weight to the most important criterion (highest percentage), as well as to the least important attribute according to the relative importance of parameters.

The basic prerequisite for use of weighting tools of GIS is the determination of weights and rating values representing the relative importance of factors and their categories. The method starts by assigning an arbitrary weight to the most important criterion (highest percentage), as well as to the least important attribute according to the relative importance of parameters. The susceptibility to flooding of the area is calculated by adding every layer with a weighted influence together and to sum all layers. Some of the causal factors can be determined systematically: from slope gradient maps those areas with the lowest slope degrees were extracted, and from curvature maps, so were the areas with no curvature as these are more susceptible to flash floods. Height level maps helped to search for the lowest topographic areas (Figure 7). After extracting, aggregating and weighting the potential causal factors influencing with different percentages of influence, an overview map was derived indicating those regions with relatively higher susceptibility to flooding due to their morphometric properties. The local lowest slope gradient and height levels were given the highest percentage of influence (30\%).

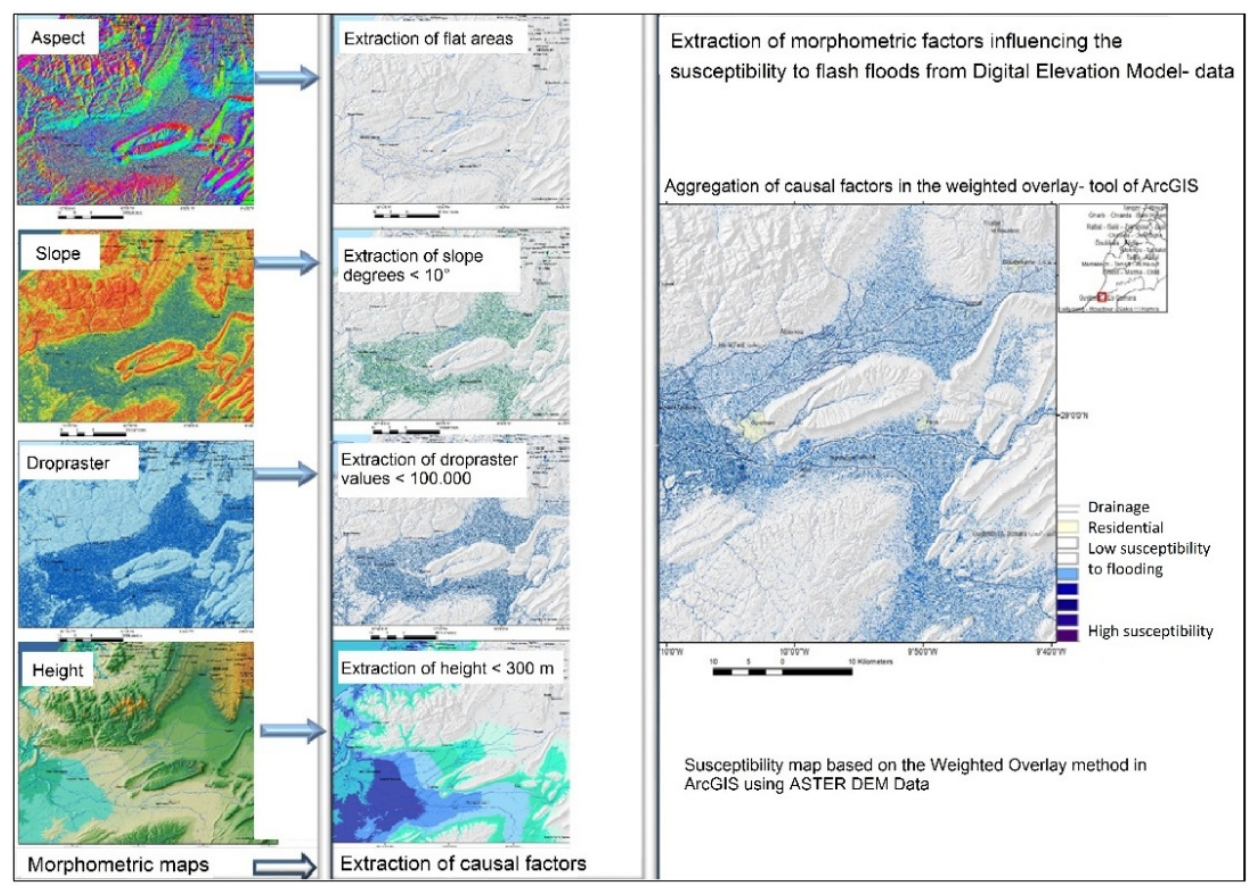

Figure 7. Weighted overlay of morphometric factors influencing the susceptibility to flooding. The resulting weighted overlay map is divided into susceptibility classes. The susceptibility to flooding is classified by values from 0 to 7 , whereby 7 is the highest, assumed susceptibility to flooding due to the aggregation of causal morphometric/preparatory factors. 
The ArcGIS-integrated hydrotools are forming an important input by allowing the hydromorphologic analysis. The mapping of morphological watersheds is an important aspect as they influence the hydromorphodynamic processes in the investigation area to a great deal. Based on SRTM and Aster DEM data the flow direction, flow accumulation and length, and watersheds were calculated as well as the drainage network.

\subsection{Digital Image Processing}

Different satellite data and image processing tools were applied in order to find out whether the satellite data can contribute to the detection of causal factors influencing the susceptibility to flooding and to pre- and post-flooding event monitoring. LANDSAT data of the Guelmim area provided by the Global Land Cover Facility/University of Maryland, USA and the Earth Explorer/USGS were used for evaluations. The free available LANDSAT data were then digitally processed, especially those from November and December 2014.

The following digital image processing tools were mainly performed:

Filter Tools: Low pass and high pass filters and directional variations were used for the detection of subtle surface structures such as meanders or landslides. Merging the "morphologic" image products derived from "Morphologic Convolution" image processing in ENVI software with RGB imageries, the evaluation feasibilities for the detection of recent sedimentary covers were improved.

Principal Component Analysis: The principal components tool was used to transform the data in the input bands from the input multivariate attribute space to a new multivariate attribute space whose axes are rotated with respect to the original space. The result of the tool was a multiband raster with the same number of bands as the specified number of components (one band per axis or component in the new multivariate space).

Normalized Difference Water Index (NDWI): Surface-soil moisture is specifically sensitive to changes in precipitation patterns. During droughts and floods extremes in surface-soil moisture can propagate into extremes in total water storage with major impacts on agricultural production and water supply. The monitoring of surface water related to flash floods and areas with high soil moisture is essential as input for a flooding hazard database. For this purpose the normalized difference water index (NDWI) is derived from Landsat data as a satellite-derived index from the near-infrared (NIR) and short-wave infrared (SWIR) channels [14], a band-ratio approach according to GAO (1996) using these two multispectral bands, and, thus, enhancing information about water bodies and near-surface soil moisture $[15,16]$. By the use of this approach, water body information can be extracted more accurately and easily than by general feature classification methods.

In the scope of this study the normalized difference water index (NDWI) was derived from Landsat 8 imageries collected with acquisition dates since 2013. After calculating the NDWI in ENVI image processing software using the bands 5 and 6 as well as 5 and 7, image products with greyscale values between 0 and 255 were created. The NDWI values were ranging from zero to 255 by assigning the lowest NDWI value in each image cube a value of zero and the maximum NDWI a value of 255. The image products were color-coded and the values of 0-255 histogram-stretched. As in the visible spectrum reflectance, characteristics of surface water can be detected easily; the result of the histogram-stretching was correlated with the visible surface water on the RGB imageries giving the 
highest NDWI value to surface water. Thus, water surfaces correspond to the highest values of the NDWI-calculation (Figure 8). Surface water and water-saturated soils are represented hereby on the chosen color table in ENVI software in this case in white. Plants with relatively higher water content appear white as well. Similar spectral response, however, is observed from larger roads and buildings. Shadows due to sun exposition of the hills can cause white to appear as well. Therefore, a careful analysis is necessary to avoid interpretation errors. In flat areas less errors can be assumed. The image products were compared not only with the corresponding RGB imageries, but also with height level and hillshade maps in order to verify the results and avoid misinterpretations. The color-coded NDWI image products were then loaded/integrated into ArcGIS. As higher values of the NDWI calculation can be correlated with higher water saturation of soils, higher groundwater tables and surface water, a request was started in ArcMap selecting all values of the NDWI grayscale image (values: $0-255$ ) above 180, .. 240, and 250). Thus, areas with relatively higher soil humidity can be detected.

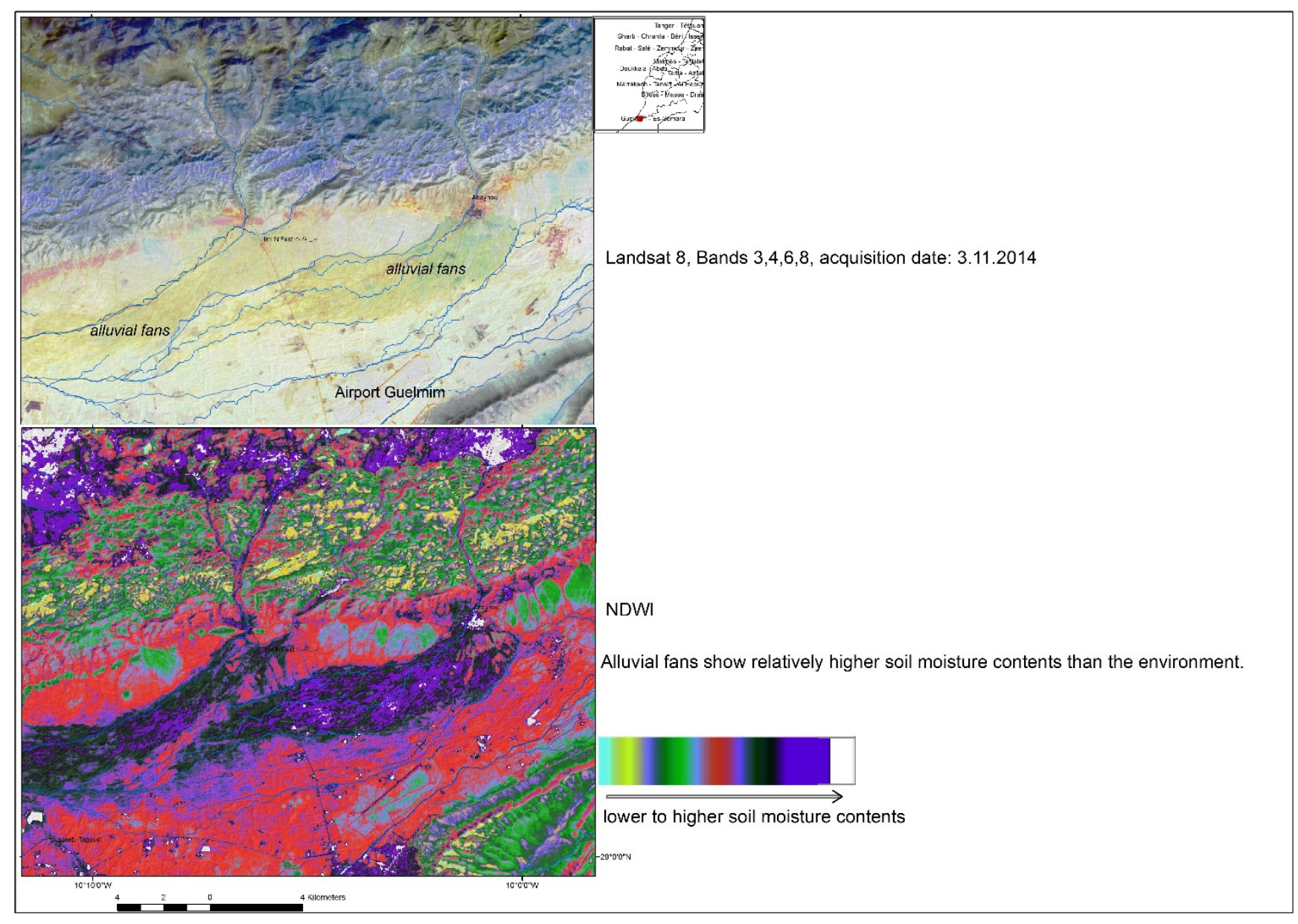

Figure 8. Landsat 8 images (3 November 2014) visualizing areas with relatively higher soil moisture using NDWI calculations using Landsat 8 bands 5 and 7 (water surfaces are presented in white, and higher soil moisture or vegetation-water content in purple). 


\section{Evaluation Results}

The evaluation results are presented here in order to demonstrate their use for the monitoring and documentation of areas prone to flash floods as input into a GIS-integrated flooding hazard database. The complex task of flash flood documentation and monitoring in the Guelmim area is supported by the combination of land surface morphometric information with spectral information from Landsat data.

\subsection{Evaluation Results Based on Digital Elevation Data}

As field investigations of A. Charif in November 2014 clearly demonstrated that the lowest and flattest areas were affected most by the flash floods, the morphometric analysis based on the digital elevation data was focused on the extraction of those terrain properties and their overlay in ArcGIS. The weighted overlay results based on SRTM (30 m resolution) data show areas where causal, morphologic factors influencing the susceptibility to flooding are aggregated (dark-blue areas in Figures 9 and 10). They show the following properties: depressions and broadervalleys situated in height levels between 200 and $300 \mathrm{~m}$, flat areas with slope degrees $<10^{\circ}$, curvature $=0$, and drop raster values $<200,000$ (values derived from calculations in ArcGIS, using the hydrology tools). The results of Figure 10 are based on a weighted overlay of the factors given the highest percentage to the height and slope gradient $(30 \%)$ and the other factors equal percentage of influence.

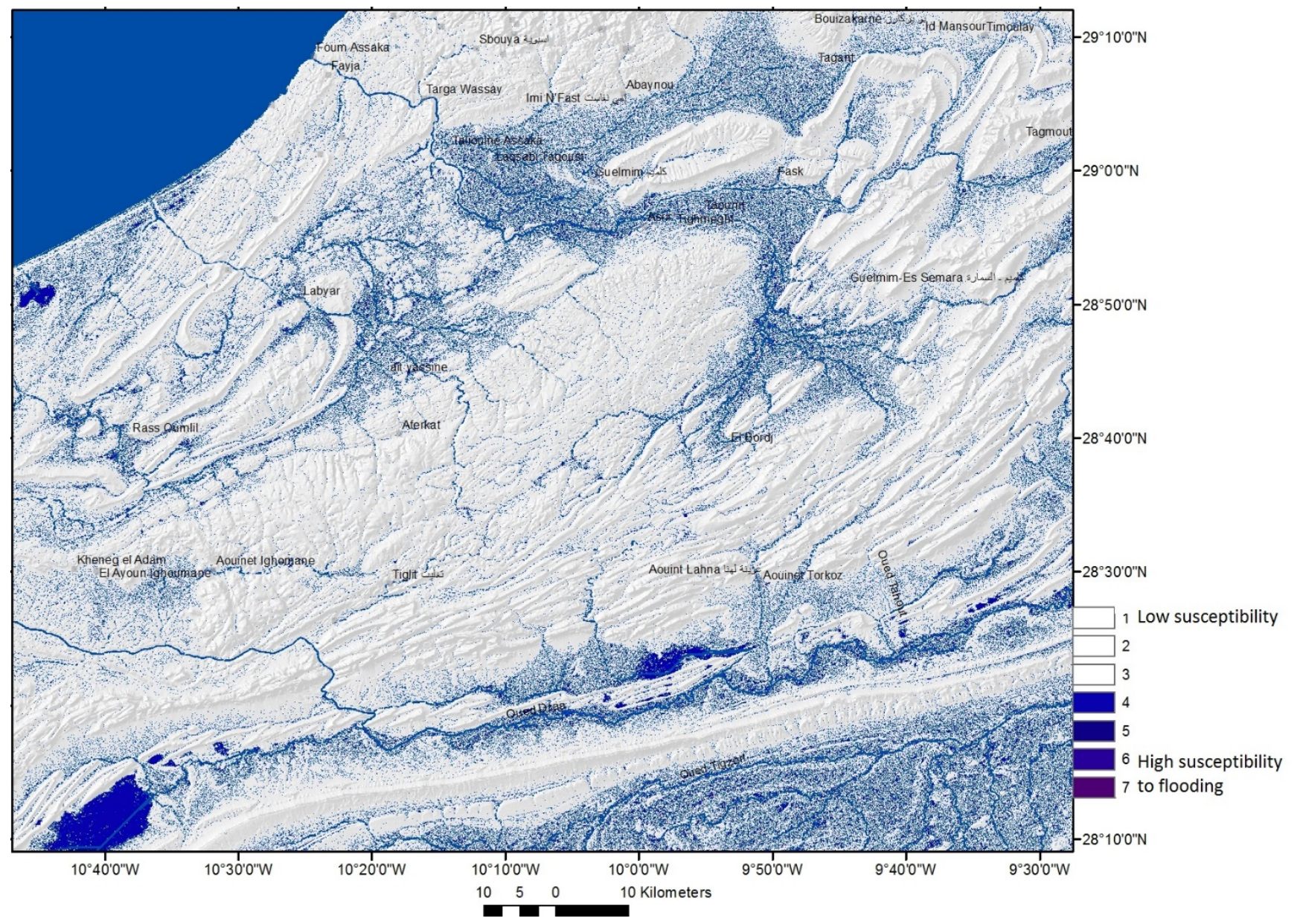

Figure 9. Areas susceptible to flooding according to their morphometric properties. 


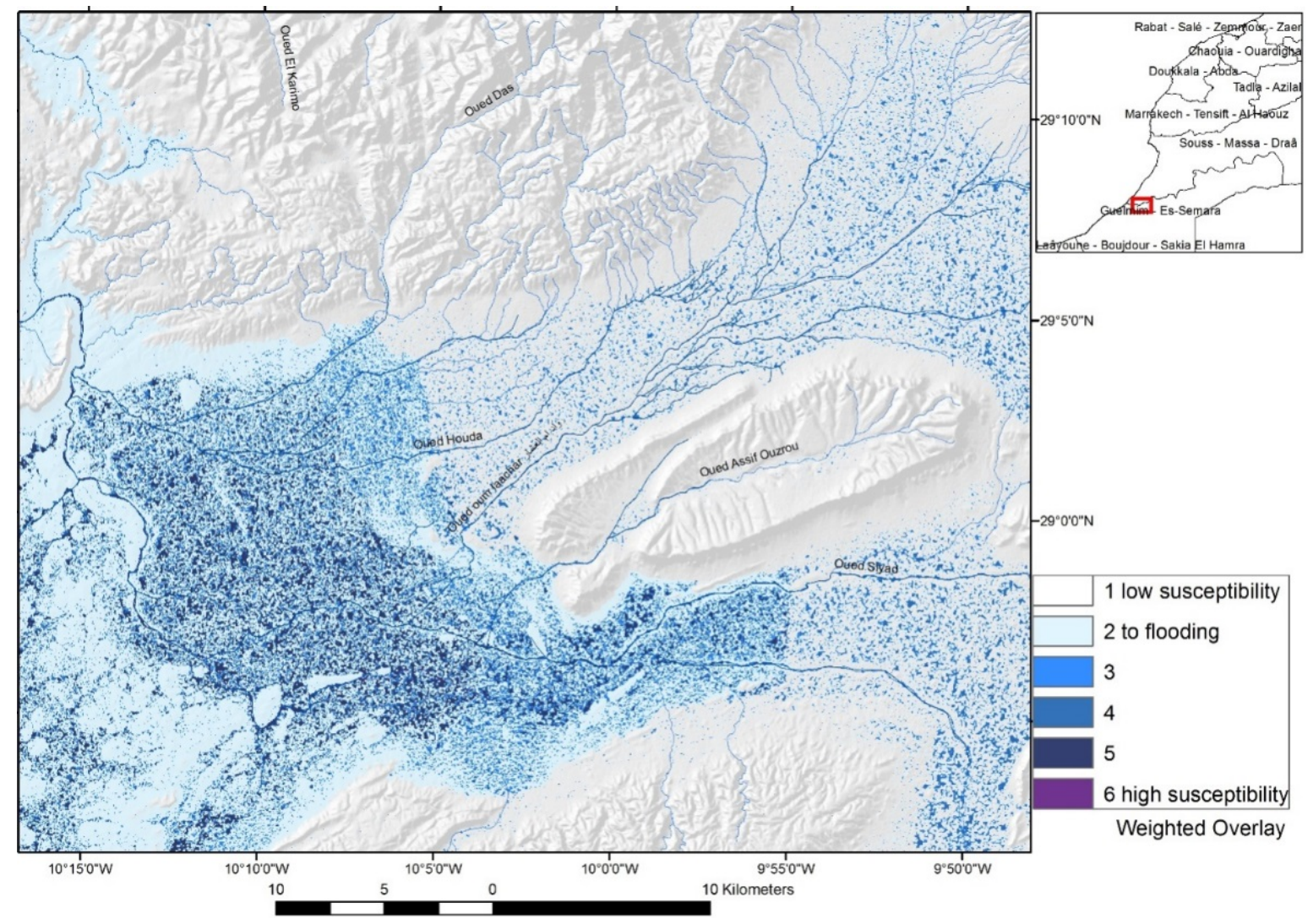

Figure 10. Areas susceptible to flooding due to the aggregation of causal, morphometric factors.

\subsection{Evaluation Results of Landsat 8 Data}

Landsat 8 imageries of the Guelmim area before and after the heavy rains in November 2014 were evaluated in order to contribute to the detection of river beds with higher sediment load due to the spectral response of recent, unconsolidated sediments (Figure 11). When comparing the Landsat 8 image from 3 November 2014 with the Landsat 8 image from 9 December 2014 (Figure 11) using Landsat 8 Band combinations of RGB 7, 6, 2, and 8 (pansharpening) the almost recent sedimentary deposits due to flash floods become visible in dark-green colors due to their characteristic spectral properties.

In Figure 12a, the principal component (PC) image is shown, that was derived from a Landsat 8 RGB image (bands 7, 6 and 3, merged with band 8, acquisition: 9 December 2014). The PC image allows the detection of recently deposited sediments in blue-violet colors by visual analysis.

When comparing the results of the weighted overlay calculations with the PC image, the occurrence of the recent sediments visible in blue-violet on the PC image coincides with areas assumed to be prone to a higher flooding susceptibility due to their morphometric disposition (Figure 12b).

The NDWI-water index image derived from the Landsat 8 (9 December 2014) data (Figure 13) visualizes that the recent sedimentary deposits obviously contain relatively higher soil moisture contents than the environment by showing the highest values (in white and violet) within these youngest deposits.

After extracting the higher NDWI values from the Landsat 8 NDWI image (9 December 2014) and comparing the result with the weighted overlay map of morphometric, causal factors (Figure 14), the comparison shows, that the areas with relatively higher NDWI values (almost related to higher soil moisture content in the upper centimeters of the sedimentary covers) are situated within those areas 
considered to be prone to to flooding on the weighted overlay map. Those areas with relatively higher soil moisture can be detected in the lowest and flattest parts of the Guelmim basin. Even after more than a week following the heavy rainfall in November 2014, remnants of the flooding such as smaller surface water bodies and areas with relatively higher soil humidity are visible in the Landsat 8 NDWI scene. Thus, by the combined use of these approaches, areas prone to flooding can be detected more precisely.

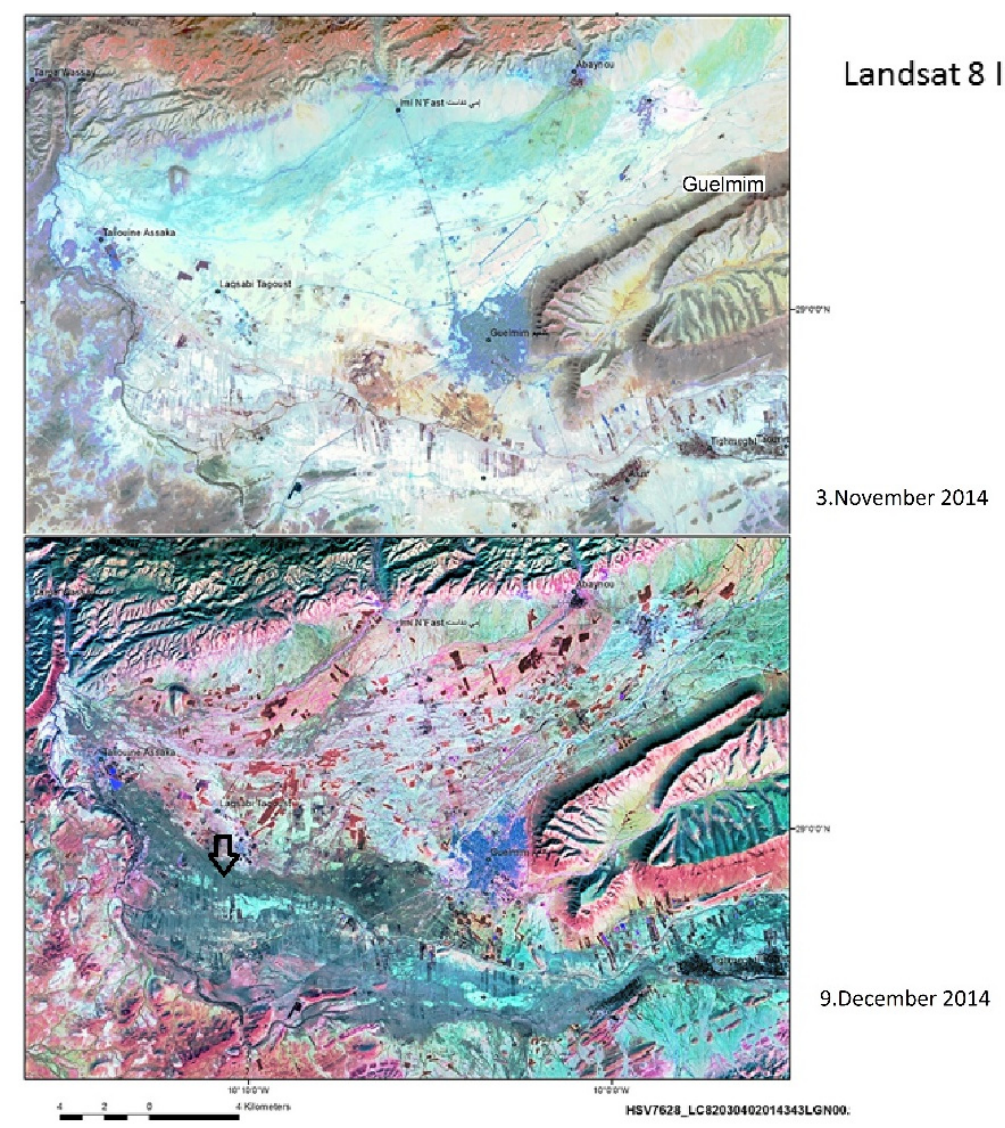

Figure 11. Comparison of the Landsat 8 RGB images (Bands 7, 6, 2+8) from 3 November 2014 and 9 December 2014. The almost recent sediments are visible in green colors on the image after the November 2014 flash floods (lower image).

The higher NDWI values in the hills in the NW of Guelmim (upper left of the images in Figure 14) might be related to higher precipitation input or to shadow effects causing errors in the evaluation process of the NDWI data.

When comparing images before and after the November flooding event, the riverbeds with recent sediment deposits can be detected due to their specific, spectral reflectivity (Figure 15, right image) on the Landsat 8 scene of 9 December 2014. Comparisons of Landsat 8 images before and after the November 2014 floods indicate road segments that were affected by the flash floods and their sedimentary deposits. This knowledge might be of importance for the mitigation of infrastructural damages such as of roads and bridges during future flooding events.

In order to contribute to the mitigation of loss and damage, those roads intersecting with drainage courses and river beds were mapped. The intersecting road sections are shown as red lines on Figure 16. 
Whenever flash floods occur again, these road segments could be blocked in time, guarded or even constructed more safely.

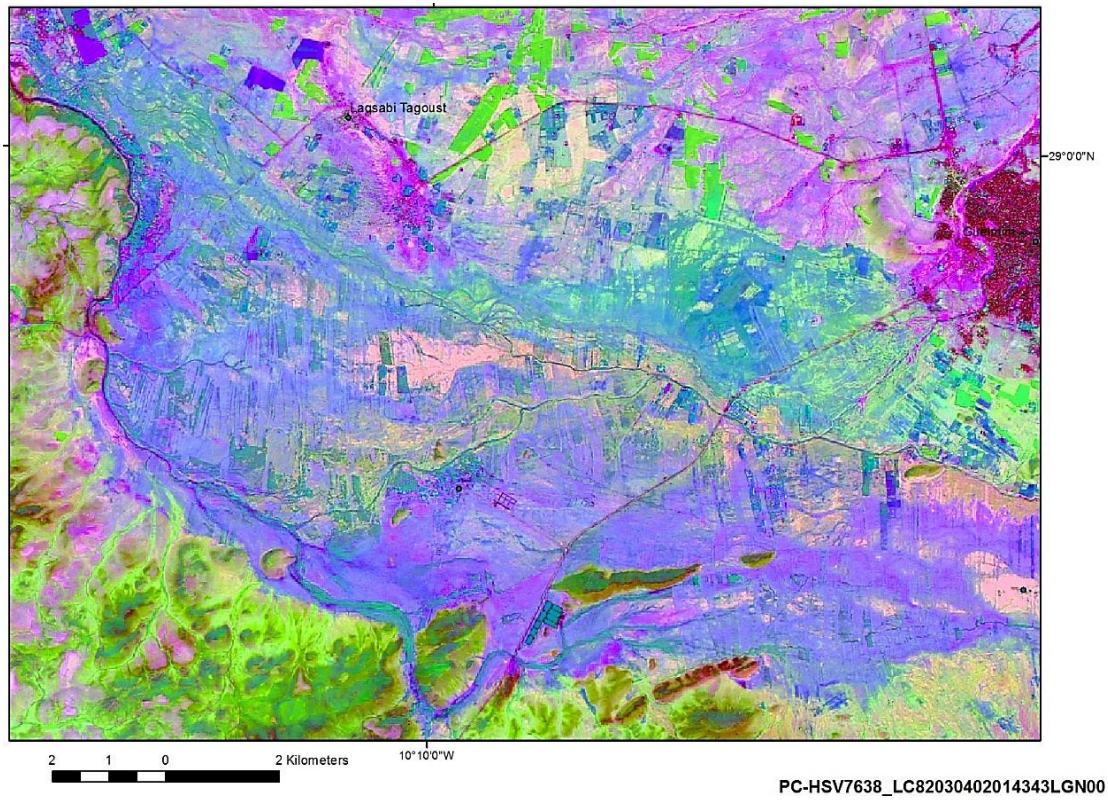

(a)

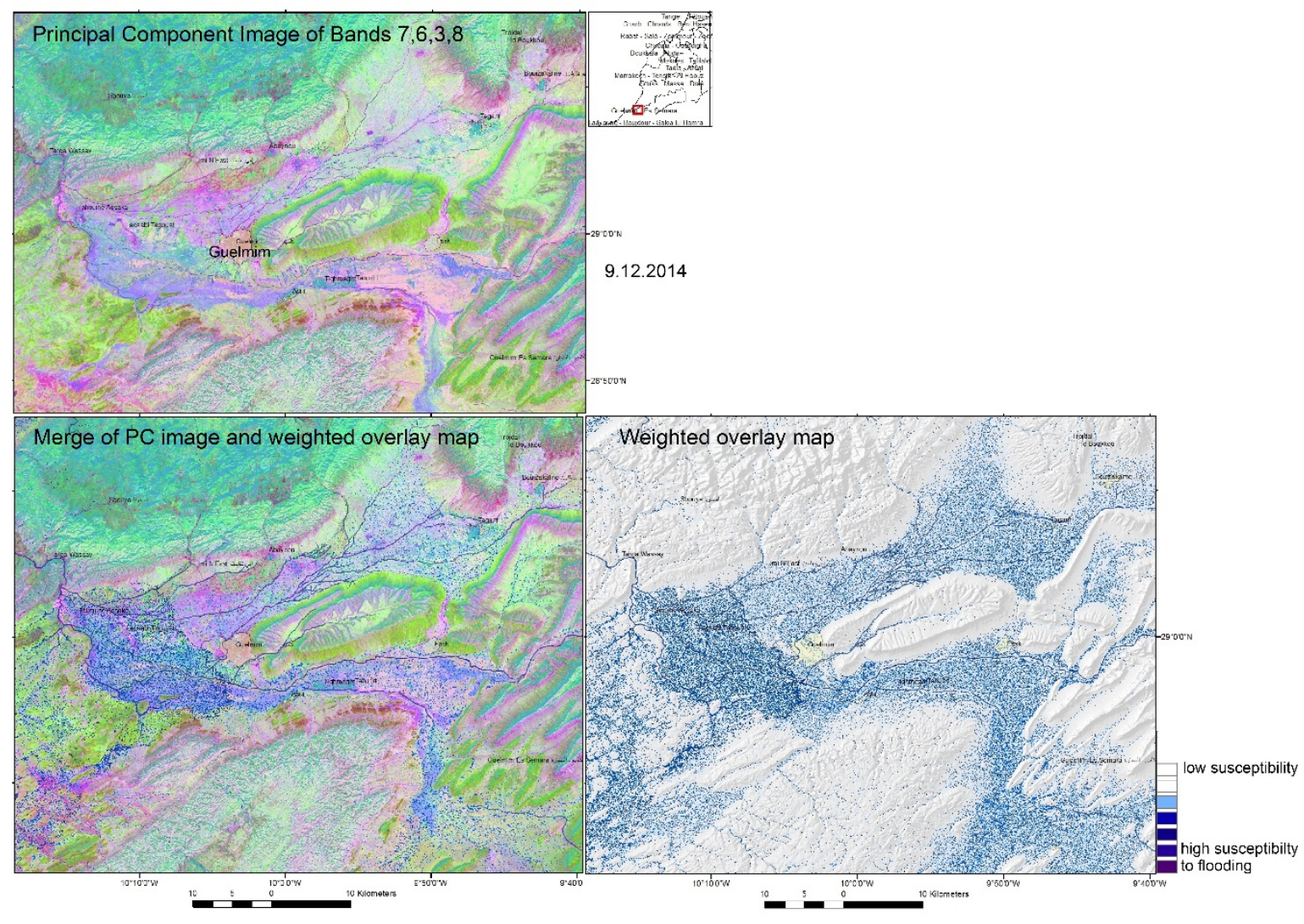

(b)

Figure 12. (a) PC Landsat 8 image showing recent sedimentary deposits (blue-violet) after the November 2014 flash floods; (b) Comparison of the weighted overlay results with the Landsat 8 principal component image. The areas with the highest susceptibility to flooding due to their morphometric properties were flooded during the November 2014 flash floods. 


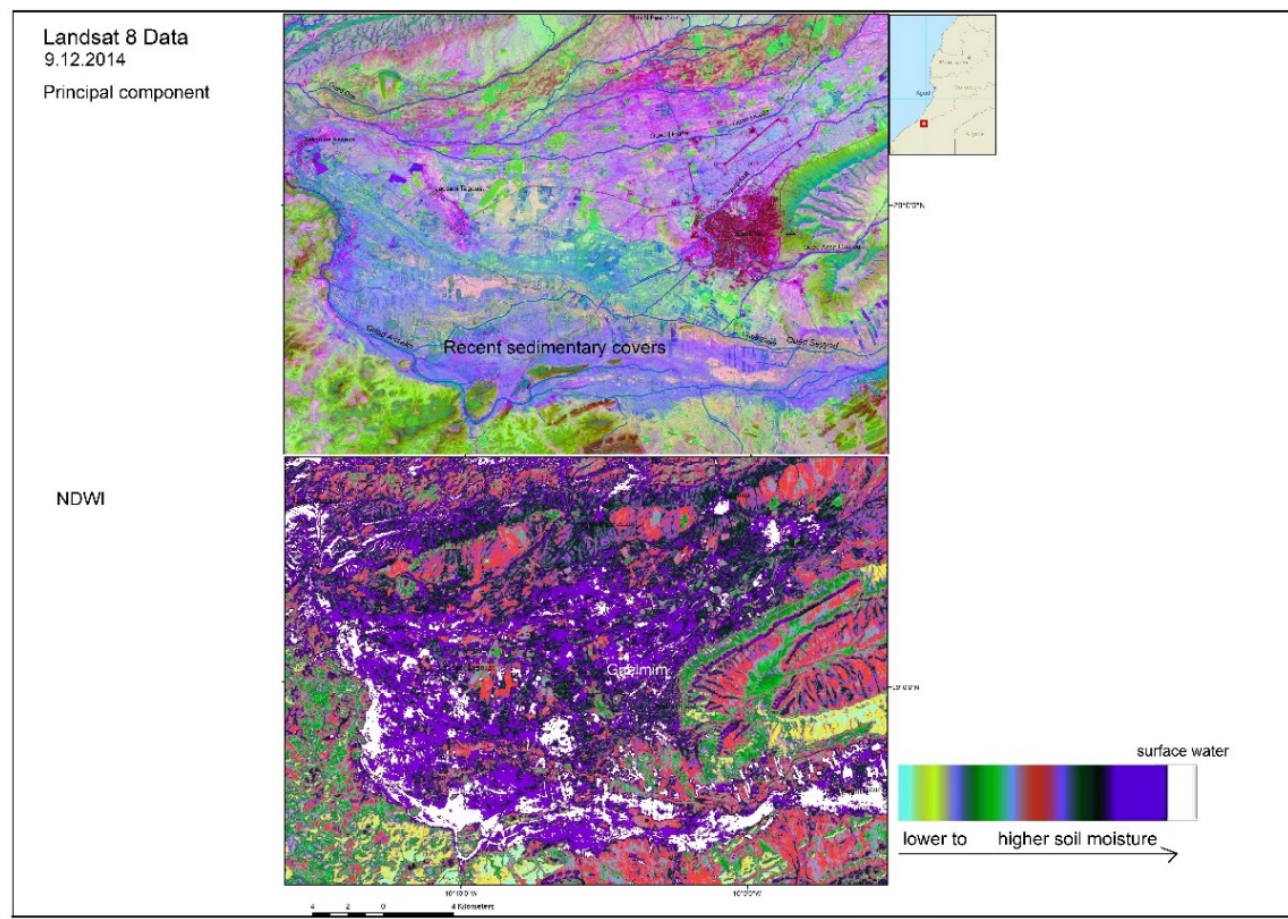

Figure 13. Landsat 8 principal component image showing recent debris flow and sediments in blue-violet colors (acquisition time: 9 December 2014) and corresponding NDWI-water index image indicating in white the highest NDWI values (lower image).
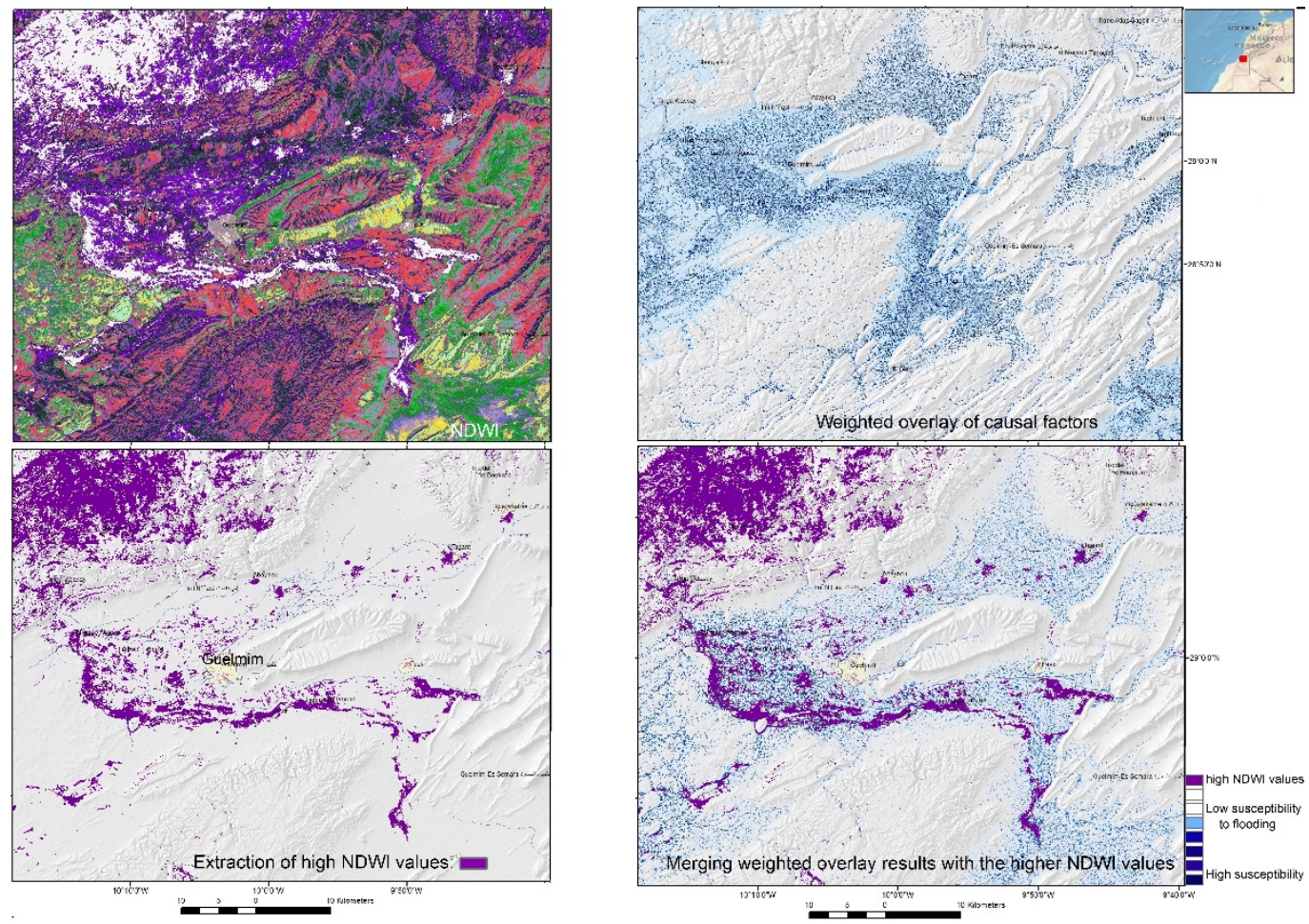

Figure 14. Overlay of the higher NDWI values with the weighted overlay results. The highest NDWI values (white, violet) within the Guelmim basin can be identified in areas with the highest susceptibility to flash floods due to their morphometric properties and disposition. 


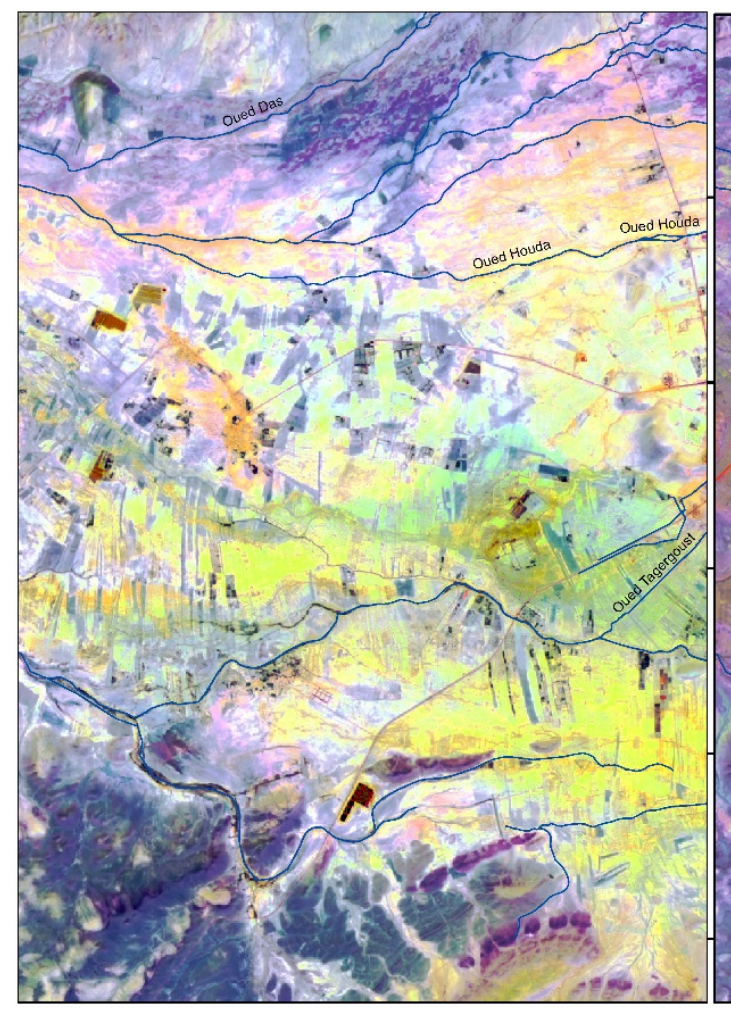

HSV-Bands 2,7,11,8_22.10.2014

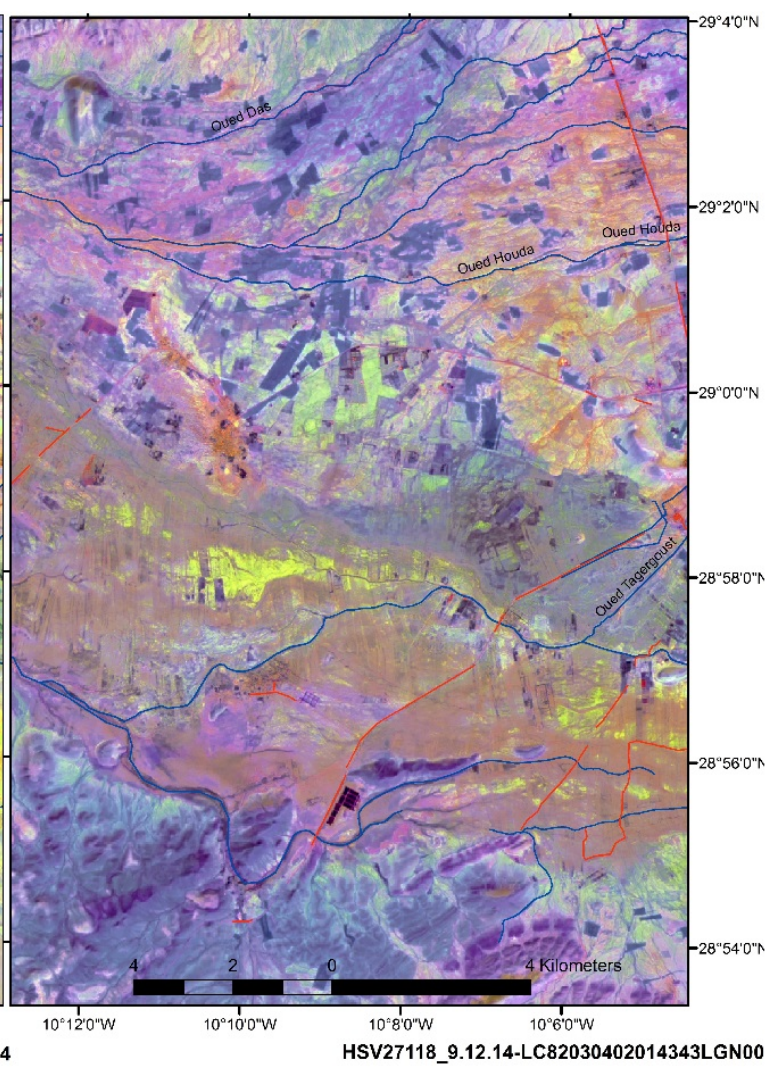

Figure 15. Road segments in flooding prone areas as visible on Landsat 8 scenes before (left image) and after the November 2014 flash floods (right image). The sedimentary deposits related to the flooding event are visible in brown colors.

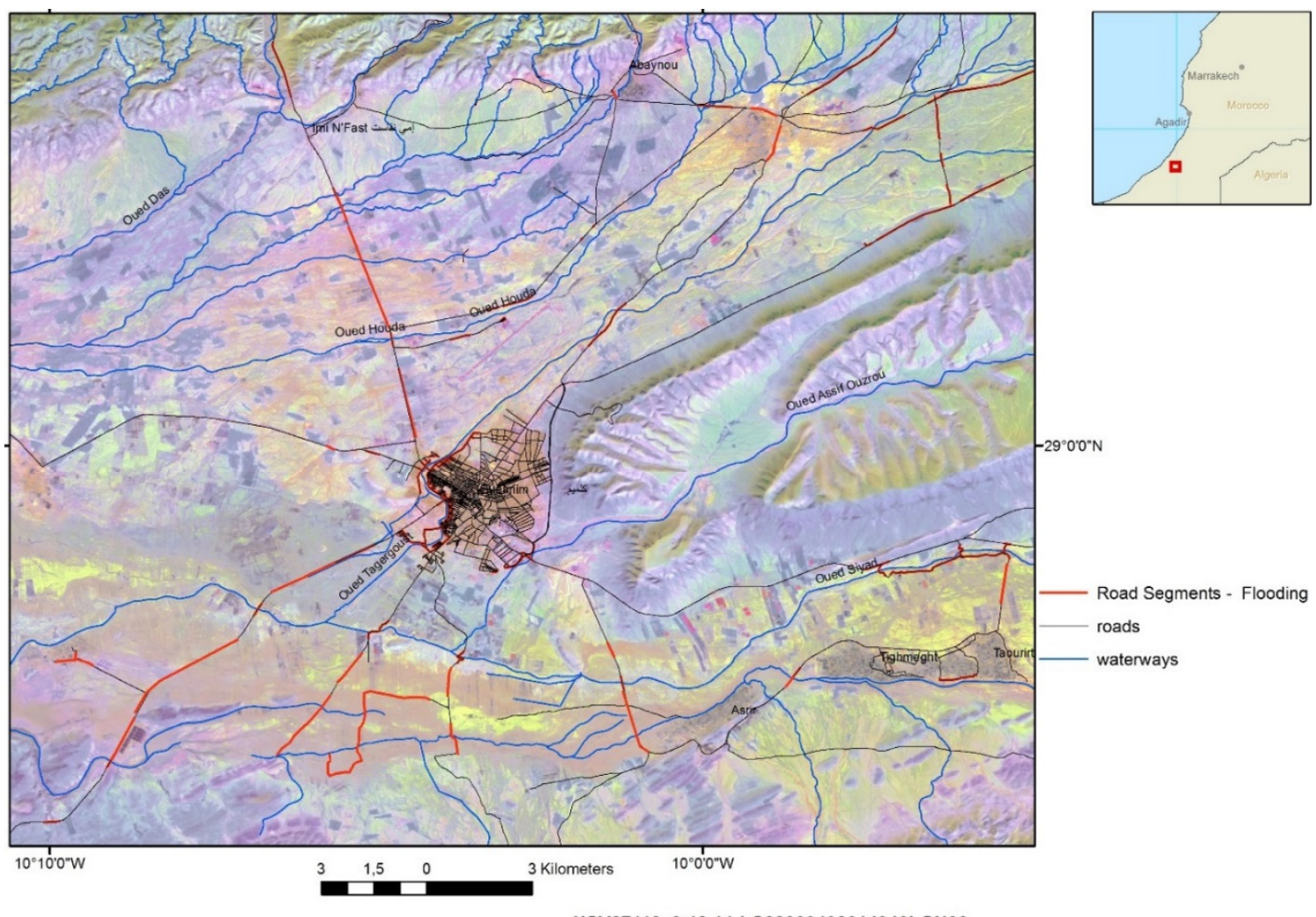

HSV27118_9.12.14-LC82030402014343LGN00

Figure 16. Roads intersecting waterways and flash flood areas (red lines). 


\section{Conclusions}

According to IPCC [17] climate change will include changing rainfall patterns and will generate more extreme climatic events such as extreme rainfall events leading to flash floods. Extreme precipitation events might occur more frequently in Morocco as well, such as that in November 2014.

Prevention of damage to human life and infrastructure related to extreme rainfall and resulting flash floods requires preparedness and mitigation measurements that should be based on a regularly updated, GIS-integrated data mining. The evaluation of satellite-gained digital elevation data contributes to the detection of areas susceptible to flooding due to their morphometric disposition. The resulting maps of weighted overlay procedures, aggregating causal, morphometric factors influencing the susceptibility to flooding (lowest height levels, flattest areas), allowed the distinguishing of areas with higher, medium and lower susceptibility to flooding. The different images derived from digital image processing of Landsat 8 data support the detection of recent sediment deposits related to the earliest flooding event in November 2014 and, thus, the detection of the extent of the flash flood-affected areas. Landsat 8 images used for the documentation of the flooding events form an essential input to a natural hazard database [18] by providing information of infrastructure (road segments, bridges, settlements) that might be affected by future flooding events. Thus, the combination of the evaluation results based on digital elevation data and satellite image data prove to be effective as an input for flash flood-hazard assessment.

\section{Acknowledgments}

This study was initiated in the scope of a collaborative research project based on the bilateral Moroccan-German Programme of Scientific Research (PMARS, 2013-2015), supported by the Moroccan Ministry of Higher Education and Scientific Research (ENSSUP) and the Federal Ministry of Education and Research (BMBF), the University of Cadi Ayyad, Safi, Morocco, and Berlin University of Technology (TU Berlin). This support is kindly acknowledged. The authors thank the reviewers of this manuscript for their efforts and contributions.

\section{Author Contributions}

Barbara Theilen-Willige wrote the remote sensing part and the GIS-integrated evaluation of the article; Abdessamad Charif, Abdelhadi El Ouahidi, Mohamed Chaibi, Mohamed Ayt Ougougdal and Halima Ait Malek were responsible for the geologic description and the field research in the study area.

\section{Appendix}

GIS-Data:

OpenStreetMap: http://download.geofabrik.de/osm/europe/

OneGeologyPortal: http://portal.onegeology.org/

http://www.diva-gis.org/gdata

http://www.arcgis.com/home/ 
Satellite Data:

ASTER DGDEM: http://www.gdem.aster.ersdac.or.jp/search.jsp

SRTM DEM: http://srtm.csi.cgiar.org/SELECTION/inputCoord.asp

LANDSAT: University of Maryland, http://glcfapp.glcf.umd.edu:8080/esdi/index.jsp

USGS: http://earthexplorer.usgs.gov/

\section{Conflicts of Interest}

The authors declare no conflict of interest.

\section{References and Notes}

1. EM-Dat. The International Disaster Database. Available online:http://emdat.be/disaster_list/ index.html (accessed on 12 December 2014).

2. Theilen-Willige, B. Use of RapidEye-Data for the Detection of Natural Hazard Prone Areas (Earthquake, Tsunami, Landslides, Desertification) in W-Morocco. Report for the German Aerospace Center and RapidEye AG, 2013, RESA-Project No. 621, doi:10.13140/2.1.1692.9604. Available online: http://resaweb.dlr.de/fileadmin/resa/documents/berichte/2012/RESA_02_2012 _0621.pdf (accessed on 18 May 2015).

3. Theilen-Willige, B.; Löwner, R.; ElBchari, F.; Wenzel, H. Remote Sensing and GIS contribution to the detection of areas susceptible to local site effects during earthquakes and to Tsunami Waves in W-Morocco. In Proceedings of the Vienna Congress on Recent Advances in Earthquake Engineering and Structural Dynamics, 2013 (VEESD 2013), Vienna, Austria, 28-30 August 2013.

4. RYOT News and Associated Press. Available online: http://www.ryot.org/severe-flash-floodingmorocco-left-least-17-dead-many-missing/874673 (accessed on 8 December 2014).

5. Climate-Data.org. Climate data for cities worldwide, Guelmim. Available online: http://en.climatedata.org/location/4101/(accessed on 8 December 2014).

6. WorldClim-Global -Free climate data for ecological modeling and GIS. Available online: http://www.worldclim.org/download (accessed on 14 December 2014).

7. Choubert, G. Histoire géologique du domaine de l'Anti-Atlas. Notes et Mémoires du Service Géologique du Maroc 1952, 100-101.

8. Dijon, R. Reconnaissances hydrogéologiques et resources en eau du bassin des Oueds Seyyad, Ouerg, Noun. Maroc Sud occidental. Notes et Mémoires du Service Géologique du Maroc 1969, no 197.154.

9. Riser, J. Anti-Atlas. Encyclopédie berbère, Anacutas-Anti-Atlas, Ed isud Volumes, 1988; pp. 776-791. Aix-en-Provence. Available online: http://encyclopedieberbere.revues.org/2522 (accessed on 17 December 2014).

10. Naser, N. Utilisation des Systeme d'Information Géographiques en Hydrogéologie en Vue de l'éboration d'un Outil de Gestion des Ressources en Eau du Bassin de Guelmim. Institut Agronomique et Veterinaire (IAV), Hassan II, Rabat, Royaume du Maroc, Memoire de Troixieme Cycle Pour l'obtention du Diplôme d'Ingénieur d'Etat en Génie Rural. Available online: http://www.spate-irrigation.org/wordpress/wp-content/uploads/2011/06/MemoireNaserNajlae _GR_2006.pdf (accessed on 17 December 2014). 
11. Theilen-Willige, B.; Ait Malek, H.; Charif, A.; El Bchari, F.; Chaïbi, M. Remote Sensing and GIS Contribution to the Investigation of Karst Landscapes in NW-Morocco. Geosciences 2014, 4, $50-72$.

12. Theilen-Willige, B.; Löwner, R.; El Bchari, F.; Ait Malek, H.; Boumaggard, E.; Chaibi, M.; Charif, A.; Nakhcha, C.; Ait Ougougdal, M.; Ridaoui, M. Remote sensing and GIS contribution to the detection of areas susceptible to natural hazards in the Safi Area, W-Morocco. In Proceedings of the 1st International Conference on Information and Communication Technologies for Disaster Management (ICT-DM'2014), Algiers, Algeria, 24-25 March 2014.

13. Theilen-Willige, B.; Ait Malek, H.; Ait Ougougdal, M.; Boumaggard, E.; Buchert, W.; Chaibi, M.; Charif, A.; El Bchari, F.; Löwner, R.; Müller, J.; et al. Remote sensing and GIS contribution to the detection of coastal areas prone to flooding hazard (tsunami and meteo-waves, storm surge, flash floods) in W-Morocco. Available online: http:/www.crts.gov.ma/sites/default/files/ geo_observateur/geoobs21.pdf (accessed on 18 May 2015).

14. Gao, B.C. NDWI-A normalized difference water index for remote sensing of vegetation liquid water from space. Remote Sens. Environ. 1996, 58, 257-266.

15. Ceccato, P.; Flasse, S.; Tarantola, S.; Jacquemond, S.; Gregoire, J.M. Detecting vegetation water content using reflectance in the optical domain. Remote Sens. Environ. 2001, 77, 22-33.

16. Ceccato, P.; Flasse, S.; Gregoire, J.M. Designing a spectral index to estimate vegetation water content from remote sensing data: Part 2. Validation and applications. Remote Sens. Environ. 2002, 82, 198-207.

17. IPCC. Climate Change 2014-Synthesis Report. Available online: http://www.ipcc.ch/pdf/ assessment-report/ar5/syr/SYR_AR5_LONGERREPORT_Corr2.pdf (accessed on 28 February 2015).

18. Löwner, R.; Theilen-Willige, B.; El Bchari, F.; Charif, A.; Aït Malek, H. Environmental risk management in the Region of Safi, Morocco. Zbl. Geol. Paläont. 2014, 12-1, 227-239.

(C) 2015 by the authors; licensee MDPI, Basel, Switzerland. This article is an open access article distributed under the terms and conditions of the Creative Commons Attribution license (http://creativecommons.org/licenses/by/4.0/). 